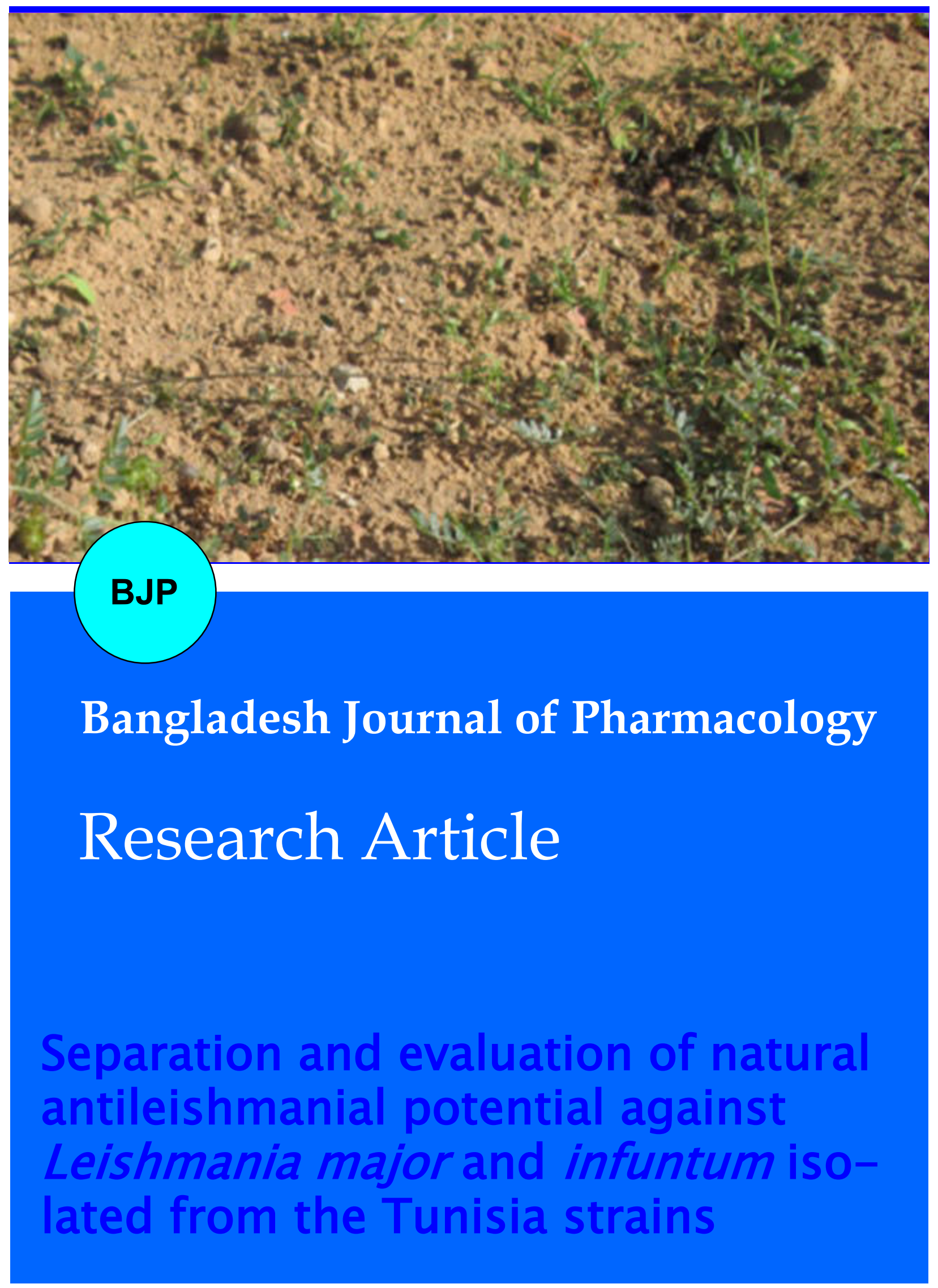




\title{
Separation and evaluation of natural antileishmanial potential against Leishmania major and infuntum isolated from the Tunisia strains
}

\author{
Salwa Bouabdallah',2, Dhafer Laouini3, Nabiha Bouzouit ${ }^{2}$, Safia El-Bok4, Rabiaa M. \\ Sghaier3, Sawssen Selmi'5, and Mossadok Ben Attia ${ }^{1}$
}

${ }^{1}$ Environmental Biomonitoring Laboratory LBE (LR01/ES14), Faculty of Sciences of Bizerta, Tunisia; ${ }^{2}$ High School of Food Industry Tunis (ESIAT), Tunisia; Tunis Faculty of Sciences, University of Tunis El-Manar, 2092 Tunis, Tunisia; ${ }^{3}$ Laboratory of Transmission, Control and Immunobiology of Infection (11 LR IPT 02), Pasteur Institute, Tunisia; ${ }^{4}$ Laboratory of Biodiversity, Biotechnology and Climate Changes, Department of Biology, Tunis Faculty of Sciences, University of Tunis El-Manar, El-Manar, 2092 Tunis, Tunisia; ${ }^{5}$ Laboratory of Bioactive Substances, Biotechnology Centre in Borj-CedriaTechnopol, BP. 901, 2050 Hammam-lif, Tunisia.

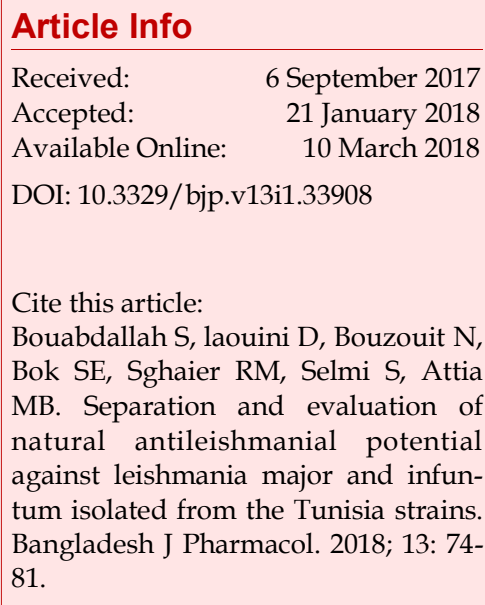

\begin{abstract}
Besides its nutritional value as a dietary supplement, Tribulus terrestris is used as a remedy for fertility disorder in Ayurveda and Chinese medicine as well as by modern herbalists. The aim of this study was to explore the biological potential (antileishmanial effect) of an extract rich in saponins from Tunisian tribulus. The chloroform extract of the various parts of T. terrestris was subjected to partial purification by solvent partitioning with ethanol and $n$ butanol. All prepared extracts were tested for their anti-leishmanial activity. The result showed that $n$-butanolic extract (saponin fraction, when isolated from leaves part) exhibited the best antileishmanial effect against both pathogenic parasites Leshmania L. major (GlC94) and L. infuntum (LV50) evaluated in vitro assessment through MTT assay. n-Butanolic extract had been detected, quantified and purified using the RP-HPLC finger print (Hypersil ODS coupled to UV-vis). High peak area (5116.82 at $3.03 \mathrm{~min}$ ) was detected at $205 \mathrm{~nm}$.
\end{abstract}

\section{Introduction}

Leishamaniasis, one of the parasitic diseases caused by trypanosomated protozoan Leishmania L. (transferred by the female phlebotomus sand fly), is one of the important health problems of Mediterranean, tropical and subtropical regions. Human taint is caused by about 21 of 30 species of the genus that infects mammals. Nearly 12 million new cases of the most common shape, cutaneous (causes skin sores) and visceral (effects internal organs of the body such as spleen, liver and bone marrow). The World Health Organization classified leishamaniasis as a major public health problem, the control of leishamaniasis left over a serious problem.

An effective vaccine versus leishmaniasis is not available, and chemotherapy is the only efficient way to treat all the forms of diseases. However, usual therapy is expensive, toxic and the resistance has emerged as a serious problem, which has pushed the researches to find new antileishmanial agents (Monozote, 2009).

The search for new natural drugs is an important field, including new less toxic and cost-effective drugs from medicinal plants, disposable to people infected with $L$. parasites. Among these medicinal plants we choose Tribulus terrestris L. T. terrestris growing in Tunisia flora as plant samples to investigate its antileishmanial 
activity related to its chemical composition.

The genus Tribulus, belonging to family Zygophyllaceae, comprises about 20 species in the world, of which three species, viz Tribulus cistoides, $T$. cistoide, $T$. terrestris), and Tribulus alatus T. alatus, are of common occurrence in India (Samuelsson et al., 1993). T. terrestrisis a well-patronized medicinal herb by Ayurveda (Tomova et al., 1981) and Peruvian Amazonia for its anti-inflammatory medicinal effect (Bonnier, 1911; Ross et al., 2010), as well as by modern herbalists (Combarieu et al., 2003). The plant is used individually as a single therapeutic agent or as a prime or subordinate component of many compound formulations and food supplements. T. terrestris (Zygophyllaceae) is an annual creeping herbaceous with a worldwide distribution shrub found in Mediterranean, subtropical, and desert climate regions in: India, China, southern USA, Mexico, Spain, and Bulgari. Known as puncture vine (Ross et al., 2010), since ancient times it was regarded as an aphrodisiac in Ayurveda therapy, thus to its beneficial claims on various ailments such as inflammations, oedema, urinary infections, and ascites (Gauthaman et al., 2008). Recently, some of the main biological molecule of Bulgarian and Chineese T. terrestris are identified and purified, including steroidal furostanol and spirostanol saponins protodioscin, terrestrinins $\mathrm{A}$ and $\mathrm{B}$, gitogenin, hecogenin, diosgenin and others. Biological value of the herbaceous was determined by the amount of the active compounds, which is varing considerably depending on the area where the plant is growing and depending on the part of plant used (Kostova et al., 2005).

Saponins are secondary metabolites which are widely distributed in the plant kingdom. They act as a chemical barrier or shield in the plant defense system to counter pathogens and herbivores (Augustin et al., 2011). Therefore, they are found in plant tissues which are able to fungal or bacterial attack and insect predation (Wina et al., 2005). Saponins divided into two major classes: Triterpenoid and steroid glycosides with a structure depending on the numbers of sugar units attached at different positions (Hostettmann and Marston, 1995). The classification and occurrence of saponins in the plant kingdom are reviewed in detail by Vincken (Vincken et al., 2007). The discovery of biological activities of saponins was not only limited to traditional uses, but more recently, in pharmaceutical and food industry applications (Güçlü-Üntündağ et al., 2007). Saponins appeared to have hemolytic, molluscicidal, anti-inflammatory, antifungal, antibacterial, antiparasitic, antiviral (Sparg et al., 2004) and mostly antitumor. They are capable to interact with targets involved in the signaling pathways leading to the apoptosis of cancer cells lines. They're used as a starting point for the semi-synthesis of steroidal drugs in pharmaceutical sectors (Sheng and Sun, 2011). The clinical significance of triterpene saponins in prevention and treatment of metabolic and vascular disease has been demonstrated. Due to the large variety of theirs structures and applications, biological effect of saponins needs to be more investigated in details by the medicinal and natural biochemists in the future (Man et al., 2010).

In general, the study of secondary metabolites derived from plants is an important field research, is requiring sophisticated tools and current approaches to precise quantify and identify bioactive molecules with high biological activities. In our last publication we have shown a strong inhibitory activity of Tunisian $T$. terrestris on ovary cancer cell lines (Bouabdallah et al., 2015), so in the present study we propose to investigate the antileishmanial effect on L. major and L. infuntum of T. terrestris according to, solvent extraction and the part of the plant used.

\section{Materials and Methods}

\section{Reagents}

Analytical grade ethanol, chloroform, acetonitril, hexane and n-butanol, obtained from Merck (Nottingham, UK), all reagents were purchased from Sigma-Aldrich-Fluka (Saint-Quentin France). The murine macrophage cell line RAW 264.7 (ATCC, TIB$71)$ was used in this work. For the chemicals, thiazolyl blue tetrazolium bromide [3-(4, 5- dimethyl thiazol-2y12, 5-diphenyltetrazolium bromide] (MTT), isopropanol, sodium dodecyl sulfate (SDS) and all reagents used for cell culture were purchased from Sigma (St. Louis, MO USA), Fluka Chemie (Buchs, Switzerland) and Merck (Nottingham, UK). (PNA) (Sigma, Saint-Quentin Fallavier, France).

\section{Biological material}

T. terrestris was collected from samples grown spontaneously in the region of "Ain-Halloufa, Boukrim Elhawaria" (north east of northern Tunisia). The sampling was conducted during (September-October 2014). The identification of the the plant was previously described as mentionned in our last publication (Bouabdallah et al., 2012; 2015).

\section{Saponin fraction extraction}

The dried and powdered plant material (powder: $30 \mathrm{~g}$ ) was extracted in a succession by chloroform at room temperature $(3 \times 270 \mathrm{~mL} \times 1$ hour $)$ and $70 \% \mathrm{v} / \mathrm{v}$ ethanol (reflux at $80^{\circ} \mathrm{C}, 3 \times 450 \mathrm{~mL} \times 2$ hours). The combined ethanol solutions were concentrated under vacuum at $70^{\circ} \mathrm{C}$ to a small volume- $150 \mathrm{~mL}$ and extracted in the separator funnel with $n$-butanol (3 times 60, 45, $45 \mathrm{~mL}$ ). The butanol layers were concentrated to dryness giving the crude fraction. 


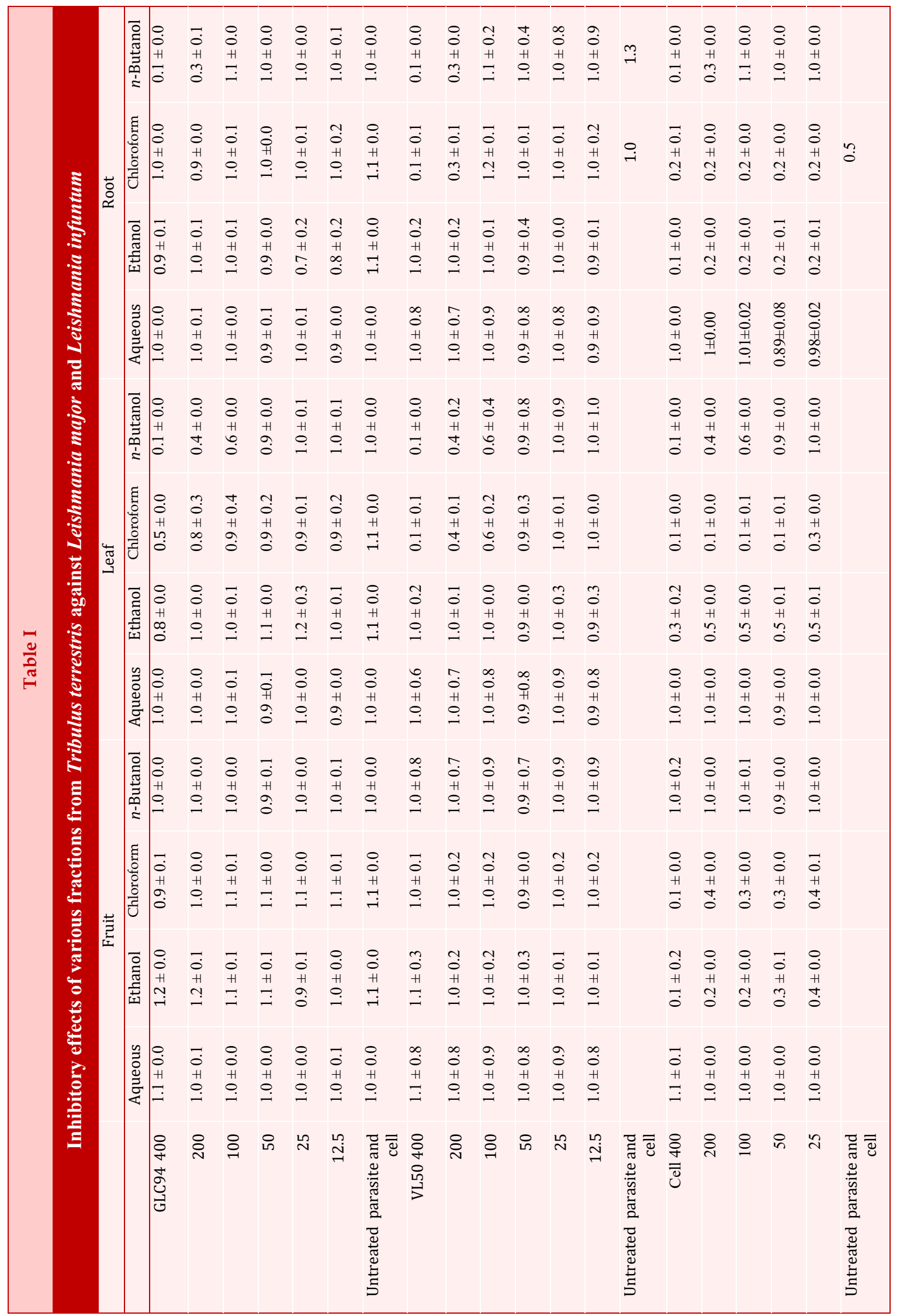




\section{Parasite culture}

L. major (MHOM/TN/95/GLC94) and L. infantum strains isolated from Tunisian patients were used. Amastigotes were obtained after passage in BALB/C mice footpad and harvested from skin lesions. Promastigote were cultured in solid medium at $26^{\circ} \mathrm{C}$, and then progressively adapted to an RPMI 1640 medium containing $10 \%$ of fetal calf serum (FCS) and supplemented with $100 \mathrm{U}$ penicillin mol/ $\mu \mathrm{L}, 100 \mu \mathrm{g}$ streptomycin mol/ $\mu \mathrm{L}$ and $2 \mathrm{mM}$ L-glutamine. With a starting concentration of $3 \times 10^{6}$ parasites $/ \mathrm{mL}$. When the stationary phase was reached, the metacyclic promastigotes were then purified as reported by (Sghaier et al., 2016) and a negative selection with peanut agglutinin (PNA). PNA- and PNA+ fractions were separated by density gradient centrifugation. The PNA- metacyclic promastigotes were then washed and diluted at the desired density.

\section{Cell and parasite treatment}

RAW 264.7 cells were dispatched at $3 \times 10^{4}$ cells/well in 96 well tissue culture plates, and kept for one night before treatment. Promastigotes parasites were washed twice with PBS, counted and dispatched at $10^{7}$ parasites/well. Cells and parasites were then incubated for 24 hours in the presence of increasing concentrations of various extracts (ranging from 12.5 to $400 \mu \mathrm{g} / \mathrm{mL}$ serially diluted). Negative controls correspond to cells or parasites cultured in the absence of plant extracts.

\section{Parasites viability assay}

The effects of extracts on $L$. promastigotes were evaluated by the MTT assay as described by Dutta (Dutta et al., 2005). After treatment with plant extracts, microtitre plates were centrifuged at $2500 \mathrm{~g}$ for $10 \mathrm{~min}$ and supernatants were removed and replaced with the same volume of $2 \mathrm{mg} / \mathrm{mL}$ of MTT freshly dissolved in PBS. Plates were incubated over night at room temperature and centrifuged at 2,500 $\times$ g. Formazan salt formed inside the parasite mitochondria was solubilized by discarding supernatants and adding SDS 20\% for 2 hours and $30 \mathrm{~min}$ at $37^{\circ} \mathrm{C}$ in the dark. Absorbance was measured at $540 \mathrm{~nm}$ using an ELISA plate reader. Optical density of each treated sample was compared to those grown without extracts. Each assay was performed in duplicate and independent experiments were realized at least twice.

\section{GC-MS analysis}

Gas chromatography-mass spectrometry (GC-MS) analysis were carried out on a gas chromatograph; an HP7890 series (II) coupled to an HP 5972 mass spectrometer (Agilent Technologies, USA) with electron impact ionization $(70 \mathrm{eV})$. Separation was carried out using phenylmethyl silox as capillary column $(30 \mathrm{~m} \times$ $0.25 \mathrm{~mm}, 0.25 \mu \mathrm{m}$ film thickness Agilent Technologies,
Hewlett-Packard, USA). Column temperature was programmed as follows $40^{\circ} \mathrm{C}$ for $1 \mathrm{~min}, 8^{\circ} \mathrm{C} / \mathrm{min}$ to $100^{\circ} \mathrm{C}$ for $5 \mathrm{~min}, 10^{\circ} \mathrm{C} / \mathrm{min}$ to $200^{\circ} \mathrm{C}$ for $3 \mathrm{~min}, 12^{\circ} \mathrm{C} /$ min to $300^{\circ} \mathrm{C}$ for $20 \mathrm{~min}$. The carrier gas was helium with a flow rate of $0.9 \mathrm{~mL} / \mathrm{min}$ and a split ratio of 100:1. Scan time and mass range were $1 \mathrm{sec}$ and 50-550 m/z, respectively. Further identification was made by matching their recorded mass spectra with those stored in the Wiley/NBS mass spectral library of the GC-MS data system and other published mass spectra. Determination of the components percentages was based on peak area normalization.

\section{Identification of biological molecule}

Further identification was made by matching their recorded mass spectra with those stored in the Wiley 9/ NIST11 mass spectral library of the GC/MS data system and other published mass spectra. Determination of the component percentages were based on peak area normalization.

\section{RP-HPLC analysis}

The bioactive compound analysis were carried out using an Agilent Technologies 1100 series liquid chromatography (RP-HPLC) coupled with an ultraviolet/visible spectrum multi wave length detector. The separation was performed on a $250 \times 4.6 \mathrm{~mm}, 4 \mu \mathrm{m}$ Hypersil ODS C18 (Thermo Fisher Scientific Inc., USA) at ambient temperature. The mobile phase consisted of acetonitrile (Solvent A) and water with $0.2 \%$ formic acid (Solvent B). The flow rate was maintained at $0.7 \mathrm{~mL} /$ min. The gradient program was as follows: 15\% A 85\% B for $0-12 \mathrm{~min}$; $40 \%$ A $60 \%$ B for $12-14 \mathrm{~min} ; 60 \%$ A $40 \%$ B for $14-18 \mathrm{~min} ; 80 \%$ A $20 \%$ B for $18-20 \mathrm{~min} ; 90 \%$ A $10 \%$ B for $20-24 \mathrm{~min}$, and $100 \%$ A $24-28 \mathrm{~min}$. Peaks were monitored at 205 and $305 \mathrm{~nm}$.

\section{Statistical analysis}

Log transformed IC80 and IC50 values for cytotoxic and antileishmanial was calculated using regression analysis and expressed as mean of $80 \%$ of cell viability, $50 \%$ inhibitory activity, respectively. Statistical significance of the differences between the treated and the control sample means were evaluated by Student's t-test and ANOVA test, for pairwise and multiple comparisons respectively. A p value $<0.05$ was considered to imply significance. All computations were performed using Excel software (Microsoft Corporation, 2003).

\section{Results}

\section{Antileishmanial activity}

Four various extract (chloroform, ethanol, n-butanol and aqueous) from different parts (leaf, seed and root) of $T$. terrestris at six concentrations $(12.5-400 \mu \mathrm{g} / \mathrm{mL})$ 


\section{Table II}

In vitro leishmanicidal and cytotoxic activities of various extracts from TT

\begin{tabular}{|c|c|c|c|c|c|}
\hline Plant & $\begin{array}{c}\text { L. infantum } \\
\text { IC }_{50} \\
(\mu \mathrm{g} / \mathrm{mL})\end{array}$ & $\begin{array}{c}\text { L. major } \\
\mathrm{IC}_{50} \\
(\mu \mathrm{g} / \mathrm{mL})\end{array}$ & $\begin{array}{c}\text { Raw264.7 } \\
\text { IC }_{80} \\
(\mu \mathrm{g} / \mathrm{mL})\end{array}$ & $\begin{array}{l}\text { selectivity index of } \\
\text { L. infantum }\end{array}$ & $\begin{array}{l}\text { selectivity index of } \\
\text { L. major }\end{array}$ \\
\hline Chloroform extract of leaf & $314.5 \pm 0.7$ & $367 \pm 0.7$ & 591.4 & 1.9 & 1.6 \\
\hline$n$-Butanol extract of root & $183.8 \pm 0.4$ & $176.5 \pm 0.3$ & $<\mathrm{IC}_{50}$ & Not available & Not available \\
\hline n-Butanol extract of leaf & $169.8 \pm 0.2$ & $227 \pm 0.1$ & $<\mathrm{IC}_{50}$ & Not available & Not available \\
\hline
\end{tabular}

was screened for their antileishmanial activity (Table I). The screening was carried out on two Leishmania species: L. major (GLC94) (Kebaier et al., 2001) and L. infantum (LV50) (Aoun et al., 2001). The cytotoxicity was evaluated by the conventional thiazolyl blue tetrazolium bromide (yellow), [3-(4, 5- diméthyl thiazol2-y12, 5-diphényltetrazolium bromide] MTT assay, according to the methods described by Mosman, so MTT will be transferred to formasan (bleu) via deshydrogenase activity (synthetized by the mitochondria of parasites).

At observation, leaf $n$-butanolic extract (saponin fraction) exhibited the best antileishmanial effect ( $L$. infuntum: $169.8 \pm 0.2 \mu \mathrm{g} / \mathrm{mL}$; L. major: $227 \pm 0.1 \mu \mathrm{g} / \mathrm{mL})$ in terms of inhibitory concentration of $50 \%$ (Table II). Given that Leishmania is an obligate intracellular parasite that affect essentially macrophages, so all extracts were also investigated for their potential cytotoxic effect towards Raw murine macrophagic 264.7 (ATCC, TIB-71) cells (as model of non-infected cell).

\section{Characterization of selectivity index}

The best extract is the one that inhibits Leishmania and presents low toxicity against raw macrophages (264.7), so three (03) extracts shown sensitive response to the drug under a concentration of $400 \mu \mathrm{g} / \mathrm{mL}$ after 72 hours of treatment against L. major and L. infuntum, only chloroformed extract has small cytotoxic effect on macrophage prompted us to define its selectivity index (SI): Against L. major and L. infuntum as follows 1.9; 1.6 (Table II).

\section{Identification of volatile compound by GC-MS}

GC-MS separation was achieved using Phenyl Methyl Silox as capillary column. The interpretation on mass spectrum GC-MS high resolution was accomplished and the spectra of the unknown component were compared to the spectrum of the known constituents stored in the WELY and NIST library. A total of 43 bioactive compounds (low proportions) were characterized and identified from $n$-butanolic extract and retention times for all mineurs peaks varied between 3.1 and $39.8 \mathrm{~min}$.

\section{Analysis of bioactive compound by RP-HPLC}

The crude extracts of T. terrestris were analysed by RPHPLC, eluting mixture of formic acid/water-acetonitrile that was tested at various compositions in an attempt to resolve the polar compounds. The result indicates that the crude sample contains nine high polar molecular peak at $205 \mathrm{~nm}$ and two peaks detected at $305 \mathrm{~nm}$. Retention times for both peaks corresponded respectively to 3.2 and $3.6 \mathrm{~min}$. Samples (peaks) were eluted with a mobile phase mixture of formic acid/ water-acetonitrile (35\% B; 65\% C). The most abundant compound at $205 \mathrm{~nm}$ is one of peak 3 (RT: $3.7 \mathrm{~min}$; Teneur: 5578.2 Mau) (Figure 1).

\section{Discussion}

During the second half of the 20th century, it was generally accepted that anti-infectious agents from medicinal plants have less side effects and thus are advantageous for therapeutic purposes than synthetic. EOs exhibited wide spectrum of biological effects such as antibacterial (Burt, 2004), antimycotic (Pisseri et al., 2008), antiviral (Lee et al., 2009) and anti-parasitic properties (Anthony et al., 2005) and even recently, they have been used as adjuvant in current anti-leishmanial therapy (Sanchez-Suarez et al., 2013). Moreover, researchers are encouraged to investigate the pharmacological activity of natural products as the traditional use agents.

T. terrestris is used in folk medicines as an aphrodisiac, it is a vital compound of Gokshuradi Guggul, tonic, palliative, diuretic, astringent, antihypertensive, stomachic, lithotriptic, and urinary disinfectant.

For the first time, we discovered the inhibitory effect of the Tribulus on the L. major and L. infuntum. Twelve extracts were prepared by sequantial extraction using different solvent such as, chloroform, ethanol, n-butanol and aqueous one. 


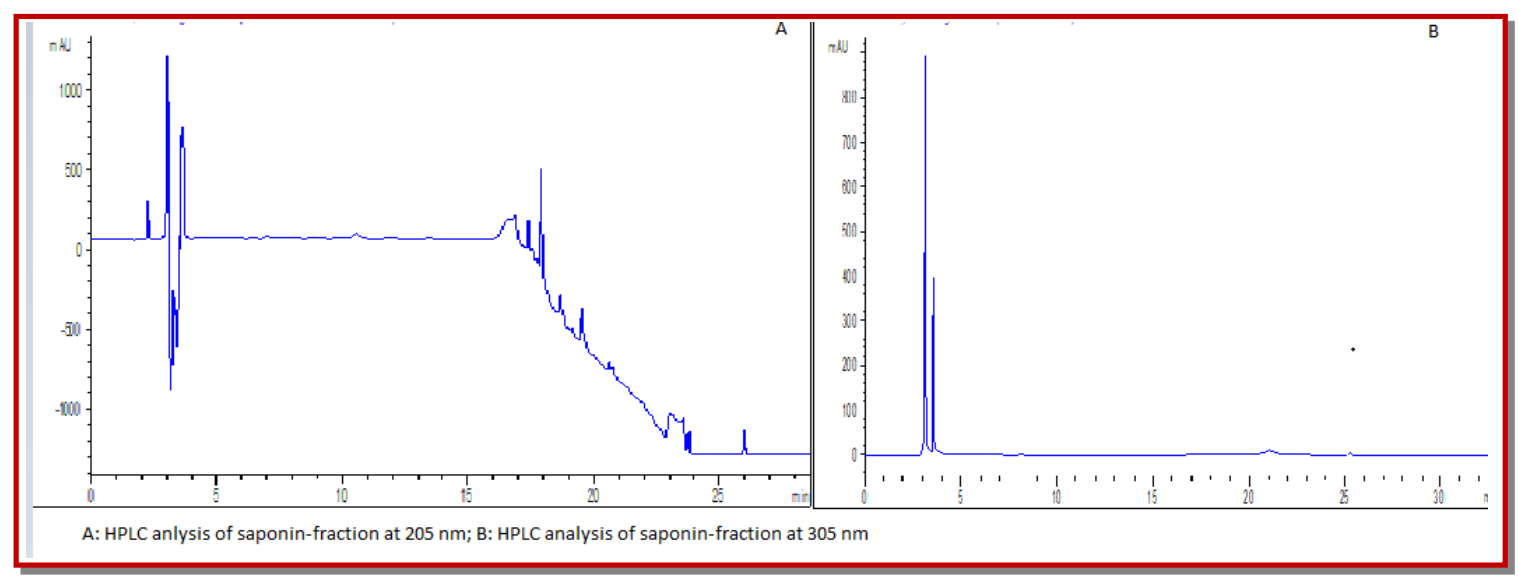

Figure 1: Analysis of bioactive compound by RP-HPLC

Chloroform extract was used to recuperate apolairmolecular like fatty-acid, chlorophyll, and caretonoids. Ethanolic fraction was prepared to recuperate polarmolecular such as flavonoids, phenolic-compounds, $n$ butanolic extract was used to concentrate saponin fraction. Our principal goal is evaluating the antileishmanial potential of $n$-butanolic fraction (saponin fraction) and comparing it with the inhibitory effect of others extracts (chloroformed, ethanolic, aqueuse). Our result showed that $n$-butanolic fraction when isolated from leaves part exhibited the best antileishmanial effect on L. major and L. infuntum.

Analysis of chemical composition of the bioactive extracts is an important stage in order to determine the properties of the major compound responsible for the biological activity. From the first interpretation we can conclude that the biological effect studied before is due to the total effect of the extract including both of the volatile and the non-volatile fraction, but this conclusion is so general and need more information. That's why we have to precise which fraction is responsible for the best activity. So, we intend to analyze the active extracts by sophisticated analytical methods adapted to each fraction isolated.

Firstly, we're going to start by studying the first hypothesis: The biological effect of the plant extract could be due to the volatile fraction. We analyzed the $n$ butanolic extract by GC-MS (gas chromatography coupled to mass spectrometry is considered as an excellent method for detection and quantification of volatile compounds) to determine the major volatile compound. Unfortunately GC-MS chromatogram showed a very poor profile of all the compounds with small proportions.

Secondly, we're going to treat the second hypothesis: The biological effect of the plant extract could be due to the non-volatile fraction. We analyzed the same extract (n-butanolic) by RP-HPLC (reversed phase liquid- chromatography used in our study is known as a sophisticated tool to detect, quantify, chemical saponin class). (Lee et al., 2009; Choon et al., 2014) in order to characterize the properties of the non-volatile compounds (Tenon et al., 2017). Fortunately the liquid chromatography profile showed an important prominent peaks detected and quantified at $205 \mathrm{~nm}$ (the wavelength that proves the existence of the saponin compound).

Based on those pratical results, we can conclude that the first hypothesis was rejected and the second one was holded back.

So, we can attribute the antileishmanial activity of $n$ butanolic extract to the synergetic effect of saponin molecules highly detected by HPLC finger print at 205 $\mathrm{nm}$.

As described in the introduction section, recently saponins have become a research hotspot due to their multiple and strong bioactivities, especially their cytotoxic activities on a series of tumor cell lines related to their chemical structure (Bouabdallah et al., 2015; Nath et al., 2016; Zhang et al., 2016; Zhou et al., 2017). However our result also confirmed that the $n$-butanolic extract (saponin fraction) exhibited the best inhibitory activity on both of the leishmania parasites tested (Table II).

Now how to explain the death of parasites generated by the effect of the saponin fraction evaluated by in vitro assay?

To explain this event, we propose to evoke two mechanisms:

The first one is the mechanism of action of synthetic molecule prescribed to the patients affected by leishmaniasis.

The second mechanism is concerning the potential targets of the saponin that kills the parasites. 
1. Amphotericin B is an antifungal polyene effective against leishmaniasis. This molecule has a mechanism of action different from other antileishmanians. It's based on a combination with the parasite ergosterol membrane which increases permeability and leads to the parasite death (Vertut-Croquin et al., 1983; Fournier et al., 1998; Gagos et al., 2001; Herec et al., 2005; Umegawa et al., 2008; Grudzinski et al., 2016).

Amphotericin B liposomale is composed of distaroyl phosphatidyl-glycerol and cholesterol. The interaction of distearoyl phosphatidylglycerol and cholesterol with a charge transfer complex present on the parasite membrane (presence of membrane sterols). Liposomal amphotericin B intercalates and stabilizes in the parasitic membrane. The liposome ruptures and releases amphotericin B then amphotericin B damages the parasitic membrane (Seibel et al., 2016).

2. Saponins are complex heterosides belonging to the cyclic terpenes or to the steroid (Cheok et al., 2014). They are divided into steroidal saponin and triterpenic saponin, the steroidal saponin are characterized by structures similar to those of the cholesterol, so they are capable to interact with sterol of cell membrane by inducing membrane pores which will modify the cellular integrity and disrupt the exchanges with the external media (Shilu et al., 2011). In the majority of cases this disorder will lead to cell death.

\section{Conclusion}

The present study reports for the first time the antileishmanial effect of the medicinal herbaceous (Tribulus) extracts and saponin fraction evaluated by in vitro assessment through MTT assay. This investigation revealed that the saponin fraction when isolated from leaves part exhibited the best inhibitory effect on $L$. major and L. infuntum. This anti-leishmanial activity was probably due to the synergetic effect of saponin molecules highly detected by HPLC finger print.

\section{Conflict of Interest}

None of the authors have any conflict of interest to declare.

\section{Acknowledgement}

We are very thankful to our collaborator Pr: Foued Azzouz owner of industrial and agriculture project (El Hawaria, Tunisia) for all advices, support and encouragement.

\section{References}

Anthony JP, Fyfe L, Smith H. Plant active components: A resource for antiparasitic agents. Trends Parasitol. 2005; 21: $462-68$.

Aoun K, Bouratbine A, Harrat Z, Belkaied M, Ali BS. Particular profile of the zymodermes of Leishmania infantum causing visceral leishmaniasis in Tunisia. Bull Soc Pathol Exot. 2001; 94: 375-77.

Augustin JM, Kuzina V, Anderson SB, Bak S. Molecular activities, biosynthesis and evolution of triterpenoid saponins. Phytochemistry 2011; 72: 435-57.

Bonnier G. Flore complète de France Suisse et Belgique de Gaston Bonnier, TomeI. librairie générale de l'enseignement, 1911; 104-10.

Bouabdallah S, Sgheier RM, Selmi S, Khalifi D, Laouni D, Attia MB. Current approaches and challenges for chemical characterization of inhibitory effect against cancer cell line isolated from Gokshur extract. J Chromatography B. 2016; 1026: 279-85.

Burt SA. Essential oils: Their antibacterial properties and potential applications in foods: A review. Int J Food Microbiol. 2004; 94: 223-25.

Choon YC, A-Karim Salman H, Sulaiman R. Extraction and quantification of saponins: A review. Food Res Int. 2014; 59: $16-40$.

Combarieu E, Fuzzati N, Lovati M, Mercalli E. Furostanol saponins from Tribulus terrestris. Fitoterapia 2003; 74: 583-91.

Dutta A, Bandyopadhyay S, Mandal C, Chatterjee M. Development of a modified MTT assay for screening antimonial resistant field isolates of Indian visceral Leishmaniasis, 2005.

Fournier I, Barwicz J, Tancrede P. The structuring effects of amphotericin B on pure and ergosterol- or cholesterolcontaining dipalmitoyl phosphatidylcholine bilayers: A differential scanning calorimetry study. Biochim Biophys Acta. 1998; 1373: 76-86.

Gagos M, Koper R, Gruszecki WI. Spectrophotometric analysis of organisation of dipalmitoyl phosphatidylcholine bilayers containing the polyene antibiotic amphotericin B. Biochim Biophys Acta. 2001; 1511: 90-98.

Gauthaman K, Ganesan A. The hormonal effects of Tribulus terrestris and its role in the management of male erectile dysfunction: An evaluation using primates, rabbit and rat. Phytomedicine 2008; 15: 44-54.

Grudzinski W, Sagan j, Welc R, Luchowski R, Wieslaw I. Gruszecki. Molecular organization, localization and orientation of antifungal antibiotic amphotericin B in a single lipid bilayer. Sci Rep. 2016; 6: 32780 .

Güçlü-Üntündağ O, Balsevich J, Mazza GP. Ressurized low polarity water extraction of saponins from cow cockle seed. J Food Eng. 2007; 80: 619-30.

Herec M, Dziubinska H, Trebacz K, Morzycki JW, Gruszecki WI. An effect of antibiotic amphotericin B on ion transport across model lipid membranes and tonoplast membranes. Biochem Pharmacol. 2005; 70: 668-75.

Hostettmann K, Marston A. Chemistry and pharmacology of natural products: Saponins. J Agric Food Chem. 1995; 53: 8093-105. 
Kebaier C, Louzir H, Chenik M, Ben Salah A, Dellagi K. Heterogeneity of wild Leishmania major isolates in experimental murine pathogenicity and specific immune response. Infect Immun. 2001; 69: 4906-15.

Kostova I, Dinchev D. Saponins in Tribulus terrestris. Chem bioactivity Rev. 2005; 4: 111-37.

Lee CL, Chiang LC, Cheng LH, Liaw CC, Abd El-Razek, MH, Chang FR, Wu YC. Influenza A $(\mathrm{H}(1) \mathrm{N}(1))$ antiviral and cytotoxic agents from Ferula foetida. J Nat Prod. 2009; 72: 1568 $-72$

Lee ST, Mitchell RB, Gardner DR, Wang Z, Azadi P, Heiss C. Isolation, characterization, and quantification of steroidal saponins in Switch grass (Panicum virgatum L.). J Agric Food Chem. 2009; 57: 2599-604.

Man S, Wenyuan G, Yanjun Z, Luqi H, Changxiao L. Chemical study and medical application of saponins as anti-cancer agents. Fitoterapia 2010; 81: 703-71.

Monozote L. Current treatment of leishmaniasis review. Open Antimicrob Agents J. 2009; 1: 9-19.

Nath LR, Gorantla JN, Thulasidasan AK, Vijayakurup V, Shah S, Anwer S, Joseph SM, Antony J, Veena KS, Sundaram S, Marelli UK, Lankalapalli RS, Anto RJ. Evaluation of uttroside B, a saponin from Solanum nigrum Linn, as a promising chemotherapeutic agent against hepatocellular carcinoma. Sci Rep. 2016; 6: 36318.

Onocha PA, Oloyede GK, Dosumu OO, Ali MS. Anti-leishmaniasis and phytotoxicity of three Nigerian Acalypha species. Arch Appl Sci Res. 2011; 3: 1-15.

Pisseri F, Bertoli A, Pistelli L. Essential oils in medicine: Principles of therapy. Parasitologia 2008; 50: 89.

Ross C, Morriss A, Khairy M, Khalaf Y, Braude P, Coomarasamy A, El-Toukhy TA. Systematic review of the effect of oral anti-oxidants on male infertility. Reprod Biomed Online. 2010; 20: 711-23.

Samuelsson G, Farah MH, Cleason P, Hagos M, Thulin M, Hedberg O, Warfa AM, Hassan AO, Elmi AH. Abderrahman AD. Inventory of plants used in traditional medicine in Somalia. IV. Plants families Passifloraceae-Zygophyllaceae. J Ethnopharmacol. 1993; 38: 1-29.

Sanchez-Suarez JF, Riveros I, Delgado G. Evaluation of the Leishmanicidal and cytotoxic potential of essential oils derived from ten Colombian plants. Iran J Parasitol. 2013; 8: 129_ 36.

Seibel NL, Shad AT, Bekersky I, Groll AH, Gonzalez C, Wood LV, Jarosinski P, Buell D, Hope WW, Walsh TJ. Safety, tolerability, and pharmacokinetics of liposomal amphotericin B in immunocompromised pediatric patients. Antimicrob Agents Chimother. 2016; 2016.
Sghaier RM, AISSA I, Attia H, Bali A, Martinez PA, Mkannaz G, Guerfeli FZ Gargouri Y, Laouini D. Treatment with synthetic lipophilic tyrosyl ester controls Leishmania major infection by reducing parasite load in BALB/c mice. Parasitology 2016; 2016.

Sheng H, Sun H. Synthesis, biology and clinical significance of pentacyclic triterpenes: A multi-target approach to prevention and treatment of metabolic and vascular diseases. Nat Pro Rep. 2011; 28: 543-93.

Sparg SG, Light ME, Van E, Staden J. Biological activities and distribution of plant saponins. J Ethnopharmacol. 2004; 94: $219-43$.

Tenon M, Feuillère N, Roller M, Birtić S. Rapid, cost-effective and accurate quantification of Yucca schidigera Roezl. Steroidal saponins using HPLC-ELSD method. Food Chem. 2017; 221: 1245-52.

Tomova M, Gyulemetova R, Zarkova S, Peeva S, Pangarova T, Simova TM. Steroidal saponins from Tribulus terrestris $L$. with a stimulating action on the sexual functions. First international conference on Chemical, Biotechnological and Biologically Active Natural Products, Proceedings Varna, 1981; 299-30.

Umegawa Y, Matsumori N, Oishi T, Murata M. Ergosterol increases the intermolecular distance of amphotericin B in the membrane-bound assembly as evidenced by solid-state NMR. Biochemistry 2008; 47: 13463-69.

Vertut-Croquin A, Bolard J, Chabbert M, Gary-Bobo C. Differences in the interaction of the polyene antibiotic amphotericin B with cholesterol- or ergosterol-containing phospholipid vesicles. A circual dichroism and permeability study. Biochemistry 1983; 22: 2939-44.

Vincken PL, Heng A, Gruppen H. Saponins, classification and occurrence in the plant kingdom. Phytochemistry 2000; 68: 275-97.

Wina E, Muetzel S, Becker K. The impact of saponins or saponin-containing plant materials on ruminant productiona review. J Agric Food Chem. 2005; 53: 8093-105.

Zhang Y, Shi C, Liu C, Yu M, Qi Y, Li S. Saponins from Panax bipinnatifidus Seem: New strategy of extraction, isolation, and evaluation of tyrosinase inhibitory activity based on mathematical calculations. J Chromatography B. 2016; 1039: 79-87.

Zhou Y, Gao X, Fu Q, Guo P, Xu X, Zhang T, Ge Y, Zhang B, Wang M, Zeng A, Luo Z, Chang C. Enrichment of total steroidal saponins from the extracts of Trillium tschonoskii Maxim by macroporous resin and the simultaneous determination of eight steroidal saponins in final the product by HPLC. J Sep Sci. 2017; 2017. 